\title{
JOB SATISFACTION IN HIGHER EDUCATION: A CASE STUDY IN SPAIN
}

\author{
Margarida Saraiva ${ }^{1}$, María de la Cruz del Río Rama ${ }^{2}$, Doina Cataraga ${ }^{3}$, José \\ Álvarez García ${ }^{4}$ \\ ${ }^{1}$ Universidade de Évora and BRU-UNIDE/ISCTE-IUL (PORTUGAL) \\ ${ }^{2}$ Universidad de Vigo (SPAIN) \\ ${ }^{3}$ Universidade de Évora (PORTUGAL) \\ ${ }^{4}$ Universidad de Extremadura (SPAIN)
}

\begin{abstract}
In the University System, the satisfaction of teachers is an essential component to increase their professional performance and achieve an adequate level of quality in the services offered to students, thus guaranteeing the proper functioning of the academic center and its results. The main objective of this research is to know the level of job satisfaction of teachers in the Faculty of Business, Finances and Tourism of the University of Extremadura (Cáceres-Spain), and as secondary objectives, to know the level of quality perceived by the teachers of the services offered to the students and to identify the motivations that prompted them to choose the teaching activity for their professional life. To reach the objectives, the methodology used is a descriptive study with a quantitative approach. After a, thorough review of the literature, the collection of the questionnaire was designed and carried out by email to the 74 teachers who formed the center's staff in the academic year 2016-2017, reaching a response rate of $79.72 \%$ (59 teachers). The analysis of the data obtained allowed to reach the proposed objectives, obtaining as main result that the teachers respondents indicated to be satisfied with their work. In relation to the quality perceived by the teachers of the services that are provided to the students, these indicate that there is a good quality of the services, being necessary to make investments in the facilities of the Center. The main motivation for the choice of the teaching career is in the first place, the vocation, followed by that teaching fits well with their skills, and thirdly, that it allows them to give a service to society.
\end{abstract}

Keywords: Job satisfaction, Higher Education, teachers, case study, Spain.

\section{INTRODUCTION}

In today's society, the concept of human resources has come to be considered as relevant as the financial capital for an organization's success, since maintaining a good team is the factor that differentiates each organization in the market [1].

[2] and [3] point out that the subject of employee satisfaction has become a common concern in all organizations and has attracted more and more attention from researchers in areas such as Organizational Psychology, Organizational Behavior and Human Resource Management, due to the positive emotional state being a fundamental factor in the life of every human being.

The job satisfaction has a significant impact on both the individual level and the organizational level, reflecting on the individual level the consequences on physical health, mental health, longevity, life satisfaction. In turn, at the organizational level is reflected in professional performance / productivity, organizational citizenship behavior (extra-paper behavior) and escape behavior [4].

In the case of higher education institutions, teacher satisfaction is a vital component for their proper functioning, since this educational agent has a decisive role as a regulator of learning and a driver of the social aspect articulated to the teaching and construction process of knowledge. In this sense, it is necessary to adequately manage the work environment in these institutions, in order to increase job satisfaction and, consequently, increase demand and reach high levels of quality of service.

This article has as main objective to analyze the level of job satisfaction among the Faculty of Business, Finance and Tourism of the University of Extremadura (Cáceres, Spain).

The article consists of four points: the first reflects the main theoretical and conceptual elements. The methods of investigation are presented in the second section, while the third item are exposed and discuss the results. Finally, we present the findings, the study limitations and avenues for future work. 